\title{
PENDUGAAN MASSA DAN VOLUME PADA BUAH ALPUKAT DAN JERUK MENGGUNAKAN PENGOLAHAN CITRA DIGITAL
}

(Prediction of Mass and Volume of Avocado and Orange Fruits Using Digital Image Processing)

\author{
Gita Sahara $^{1}$, Darwin ${ }^{1}$, Indera Sakti Nasution ${ }^{1 *}$ \\ ${ }^{1}$ Program Studi Teknik Pertanian Fakultas Pertanian, Universitas Syiah Kuala \\ *Corresponding author: I.Nasution@unsyiah.ac.id
}

\begin{abstract}
Abstrak. Penelitian ini bertujuan untuk menduga massa dan volume buah alpukat dan jeruk menggunakan pengolahan citra digital. Pada penelitian ini terdapat tiga ukuran pada buah alpukat dan jeruk yaitu: besar (A), sedang (B) dan kecil (C), dengan menggunakan sampel buah masing-masing sebanyak 30 buah untuk data training dan 15 buah untuk data testing. Pengambilan citra menggunakan kamera Charge Coupled Device (CCD) dalam format bitmap. Data citra diolah menggunakan Software Halcon MVTecversi 11(demo) dengan memasukkan algoritma metode bentuk buah (eccentricity) dan algoritma metode irisan. Hasil penelitian pada pendugaan massa dan volume buah alpukat menggunakan metode eccentricity diperoleh tingkat rata-rata akurasi masing-masing sebesar $94,12 \%$ dan $92,85 \%$. Sedangkan menggunakan metode irisan diperoleh tingkat rata-rata akurasi masa dan volume masing-masing sebesar $93,60 \%$ dan $94,00 \%$. Pendugaan massa dan volume buah jeruk menggunakan eccentricity diperoleh tingkat rata-rata akurasi masing-masing sebesar $96,58 \%$ dan $93,08 \%$. Sedangkan menggunakan metode irisan diperoleh tingkat rata-rata akurasi masa dan volume masing-masing sebesar $92,54 \%$ dan $90,30 \%$
\end{abstract}

Kata kunci :Alpukat, Jeruk, Pengolahan Citra.

Abstract. This study aims to estimate the mass and volume of avocados and oranges using digital image processing. In this study there were three sizes of avocados and oranges, such as: large (A), medium (B) and small (C), by using 30 fruit samples of each fruit for training data and 15 fruits for testing data. The image was captured using a camera's Charge Coupled Device (CCD) in a bitmap format. Image data was processed using Halcon MVTec version 11 (demo) software using eccentricity and slice method algorithms. The results of the study on estimating the mass and volume of avocados using the eccentricity method obtained an average level of accuracy were $94.12 \%$ and $92.85 \%$. While by using the slice method, the average mass and volume accuracy rates were $93.60 \%$ and $94.00 \%$. Estimating the mass and volume of oranges using eccentricity method obtained an accuracy average of $96.58 \%$ and $93.08 \%$. While by using the slice method, the average level of accuracy and volume were $92.54 \%$ and $90.30 \%$ respectively.

Keywords: Avocados, Oranges, Image Processing.

\section{PENDAHULUAN}

Saat ini industri pengolahan hasil pertanian dan perkebunan berkembang sangat pesat. Salah satunya dipengaruhi oleh kegiatan pasca panen yang erat kaitannya dengan mutu produk yang dihasilkan, yang pada akhirnya menentukan pula harga jual yang dapat diterima oleh petani. Tahapan proses pengolahan hasil perkebunan pasca panen adalah pemilihan produk berdasarkan kualitas yang dapat menjamin keseragaman mutu dari suatu produk. Beberapa parameter yang menentukan mutu dari buah-buahan adalah parameter tingkat usia tanam, ukuran fisik, bentuk dan tingkat kematangannya (Kementerian Pertanian, 2012).

Karakteristik fisik dari produk pertanian adalah parameter yang paling penting dalam menentukan standar desain grading, pengangkutan, pemrosesan, dan sistem pengemasan yang tepat. Sifat fisik utama dari buah jeruk adalah bentuk, ukuran, kepadatan, porositas, volume, dan massa buah serta gesekan terhadap berbagai permukaan (Akar et al., 2005). Dalam ukuran buah, massa, volume, dan kepadatan agak berkolerasi. Volume dan massa 
bersama untuk menentukan kepadatan buah yang berhubungan untuk menghasilkan konsistensi dan rasa. Volume juga bisa digunakan untuk prediksi waktu panen (Hahn et al., 2000).

Secara tradisional, volume dan massa buah dapat diperkirakan secara manual dengan metode perpindahan airdan menggunakan timbangan digital.Sistem grading dan penyortiran buah berdasarkan computer vision (CV) berpotensi sebagai pengganti pada pengukuran manual dalam industri pengemasan buah dan ekspor. Tujuan utama dari sistem penyortiran tersebut adalah untuk menyortir buah-buahan berdasarkan parameter kualitasnya. Beberapa parameter seperti warna, ukuran, bentuk, volume, massa, luas permukaan, dan cacat tersembunyi ikut berperan dalam mempertimbangkan kualitas buahbuahan(Venkatesh et al., 2015).

Perkembangan metode pengolahan citra telah banyak digunakan dalam bidang pertanian, khususnya dalam proses sortasi dan grading buah dan hasil pertanian lainnya. Pengolahan citra dilakukan dengan memasukkan algortima yang disusun berdasarkan parameter yang digunakan dan melakukan pengolahan pada satu citra ke citra lainnya (Ahmad, 2005). Pengembangan metode tersebut dapat mempermudah pemilihan ukuran buah dengan waktu yang lebih singkat jika dibandingkan dengan pengamatan secara langsung dengan peralatan sederhana.Tujuan dari penelitian ini adalah untuk menduga massa dan volume buah alpukat dan jeruk menggunakan pengolahan citra digital.

\section{METODE PENELITIAN}

\section{Waktu dan TempatPenelitian}

Penelitian dilaksanakan pada bulan September sampai dengan Desember 2018. Tempat pelaksanaan penelitian di Laboratorium Teknik Pasca Panen, Prgogram Studi Teknik Pertanian, Fakultas Pertanian, Universitas Syiah Kuala, Darussalam, Banda Aceh.

\section{Alat dan Bahan}

Alat yang digunakan pada penelitian adalah gelas ukur $1000 \mathrm{ml}$ dan $200 \mathrm{ml}$, laptop Asus dengan processor: Intel(R) Core(TM) i3-6006U CPU @ 2.00GHz RAM 4GB, jangka sorong, timbangan digital, lampu neon 5 watt, kamera Charge Coupled Device (CCD) dan dan software Halcon $M V T e c$ versi 11(demo). Bahan yang digunakan pada penelitian adalah buah Alpukat dan Jeruk masing-masing sebanyak 45 buah.

\section{Pengumpulan Persiapan Bahan}

Pada penelitian ini terdapat tiga ukuran pada buah alpukat dan jeruk berdasarkan SNI yaitu: besar (A), sedang (B) dan kecil (C), sampel buah yang digunakan masing-masing sebanyak 30 buah untuk data training dan 15 buah untuk data testing. Setelah buah alpukat dan buah jeruk dikumpulkan, dilakukan pembersihan kotoran yang terdapat pada permukaan buah, kemudian dilakukan sortasi berdasarkan kriteria ukuran yang telah ditentukan.

\section{Pengambilan Citra BuahAlpukat dan Jeruk}

Pengambilan citra buah alpukat dan buah jeruk dengan menggunakan kamera Charge Coupled Device (CCD) yang diletakkan tegak lurus dengan jarak $130 \mathrm{~cm}$. Backgorund yang digunakan adalah karton berwarna putih, dengan tambahan pencahayaan dari lampu neon 5 watt. Ukuran citra yang diperoleh adalah 1280 x 720 piksel dalam format bitmap. 


\section{Pengolahan Citra}

Proses pemisahan antara objek dan background menggunakan metode Otsu. Metode ini merupakan teknik yang paling sederhana dalam proses segmentasi, sehingga dapat lebih mudah digunakan. Metode ini melakukan pembagian wilayah-wilayah untuk mengenali objek dan background. Proses pengolahan citra dan identifikasi dilakukan dengan bantuan software Halcon MVTec versi 11(demo).

\section{Pendugaan Massa dan Volume Buah Berdasarkan Kriteria Bentuk Buah (eccentricity) \\ Transformasi Citra Warna}

Transformasi model warna RGB (red, green, blue) ke model warna abu-abu (grayscale). Citra digital abu-abu pada setiap pikselnya mempunyai gradasi warna mulai dari warna putih sampai warna hitam, dimana rentang warna tersebut menyatakan setiap piksel dapat diwakili oleh 8 bit atau 1 byte. Rentang warna pada abu-abu (greyscale) sangat cocok bila digunakan untuk proses pengolahan file gambar. Warna abu-abu sebenarnya merupakan hasil rata-rata dari model warna R (red), G (green), B(blue).

\section{Penentuan Bentuk Objek}

Penentuan bentuk objek bertujuan untuk mengetahui bentuk objek yang akan dianalisis. Pada penelitian ini lebih difokuskan pada bentuk bola dan elips. Untuk menentukan apakah bentuk objek adalah bola dan elips digunakan nilai eccentricity. Nilai eccentricity (e) merupakan perbandingan nilai jari-jari sumbu mayor objek dengan nilai jari-jari sumbu minor, dihitung dengan menggunakan persamaan:

$$
e=\frac{c}{a}
$$

Dimana:

$$
\begin{aligned}
& \mathrm{a}=\text { nilaijari-jarisumbu mayor } \\
& \mathrm{b}=\text { nilaijari-jarisumbu minor } \\
& \mathrm{c}=\sqrt{a^{2}-b^{2}}
\end{aligned}
$$

Menurut Iqbal, dkk. (2011), membuat kriteria untuk penentuan eccentricity bentuk buah berdasarkan kisaran tertentu seperti pada Tabel1.

Tabel 1. Kriteria bentuk model buah (Iqbal, dkk. 2011)

\begin{tabular}{ccc}
\hline Eccentricity & Rasio b/a & Bentukbuah \\
\hline$<0.3$ & $0.95-1.05$ & Bola \\
$0.3-0.7$ & $0.7-0.95$ & Elips \\
\hline
\end{tabular}

\section{Prediksi Volume}

Prediksi volume buah dengan menggunakan pengolahan citra digital dapat dicari dengan menggunakan rumus sebagai berikut:

a. Berbentuk bola

$$
\text { Volume bola }=\frac{4}{3} * \pi * a^{3}
$$

Dimana:

$$
a=\text { nilai jari-jari }
$$


b. Berbentuk elips

$$
\text { Volume bola }=\frac{4}{3} * \pi * a b^{2}
$$

Dimana:

$a=$ nilai jari-jari sumbu mayor

$\mathrm{b}=$ nilai jari-jari sumbu minor

\section{Pendugaan Massa dan Volume Buah Berdasarkan Metode Irisan Tranformasi Citra Warna}

Transformasi model warna $\mathrm{R}$ (red), $\mathrm{G}$ (green), $\mathrm{B}($ blue) ke model warna L*a*b* sebelum konversi warna RGB ke model $\mathrm{L}^{*} \mathrm{a}{ }^{*} \mathrm{~b} *$ terlebih dahulu dikonversi model warna RGB ke model warna CIE XYZ (Plataniotis, 2000):

$\begin{array}{lrlll}X & 0,4125 & 0,3576 & 0,1804 & R \\ Y=0,2127 & 0,7152 & 0,0722= \\ Z & 0,0913 & 0.1192 & 0,9502 & B\end{array}$

Tahapan selanjutnya adalah mengkonversi ke model warna CIE Lab dengan persamaan (Plataniotis, 2000):

$\mathrm{L}^{*}=116 f\left(\frac{Y}{Y_{n}}\right)-16$

$\mathrm{a}^{*}=500\left[f\left(\frac{x}{x_{n}}\right)-f\left(\frac{z}{z_{n}}\right)\right]$

$\mathrm{b}^{*}=200\left[f\left(\frac{Y}{Y_{n}}\right)-f\left(\frac{Z}{z_{n}}\right)\right]$

Keterangan:
$f(s)=s^{1 / 3}$
untuk $\mathrm{s}>0,008856$
$f(s)=7,7872+16 / 116$
untuk $\mathrm{s} \leq 0,008856$

\section{Prediksi Volume}

Menurut Riddle (1979) untuk melakukan perhitungan volume dengan menggunakan teknik irisan maka dapat digunakan persamaan (8). Volume setiap irisan kemudian dijumlahkan untuk memperkirakan volume total seperti yang ditunjukkan pada persamaan (9). Prediksi volume buah dengan menggunakan pengolahan citra digital dapat dicari dengan menggunakan rumus sebagai berikut:

$\mathrm{A}_{\mathrm{i}}=\pi\left(\frac{\Delta y}{2}\right)^{2}$

$\mathrm{V}_{\mathrm{i}}=\mathrm{A}_{\mathrm{i}} \Delta x$

$\mathrm{V}=\sum_{i=1}^{n} V i$

Keterangan :

$\mathrm{Ai}=$ Luas penampanganirisan

$\mathrm{Vi}=$ Volume masing-masingirisan

$\Delta \mathrm{y}=$ Diameter irisan

$\Delta \mathrm{x}=$ Ketebalanirisan 


\section{Prediksi Massa dan Volume Berdasarkan Kolerasi Antarparameter}

Untuk mengetahui tingkat hubungan antara hasil pengukuran manual dan pengolahan citra digunakan analisa kolerasi regresi linier yang dinyatakan dengan persamaan regresi. Dari analisa kolerasi ini didapatkan koefisien kolerasi dan persamaan regresi antarparameter, yang nantinya dapat digunakan juga untuk memprediksi nilai massa dan volume buah alpukat dan jeruk berdasarkan hubungan parameter yang digunakan.

\section{HASIL DAN PEMBAHASAN}

Untuk menduga massa dan volume buah alpukat dan jeruk, digunakan 2 pendekatan yaitu : berdsarkan bentuk buah (eccentricity) dan berdasarkan irisan buah. Algoritma yang dibangun berdasarkan kedua pendekatan tersebut menduga volume citra buah dalam bentuk piksel ${ }^{3}$. Volume citra buah tersebut dibandingkan dengan pengukuran secara manual untuk memproses model pendugaan yang terbaik. Dalam hal ini dilakukan pengukuran massa buah dan volume buah secara manual. Hasil hubungan antara volume citra dengan massa dan volume buah secara manual dapat dilihat pada Gambar 1,2,3, dan 4.

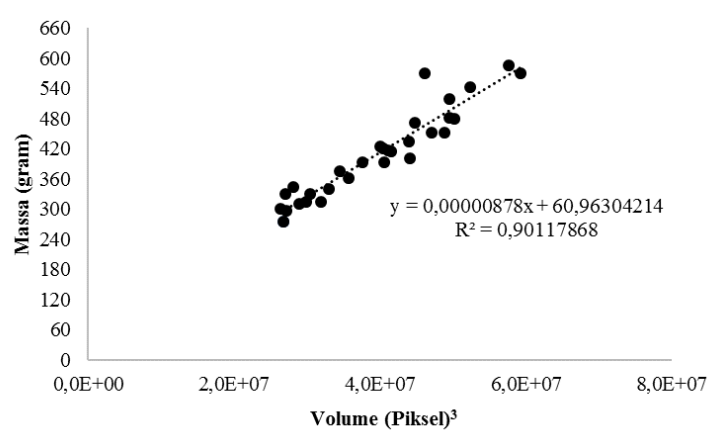

(a)

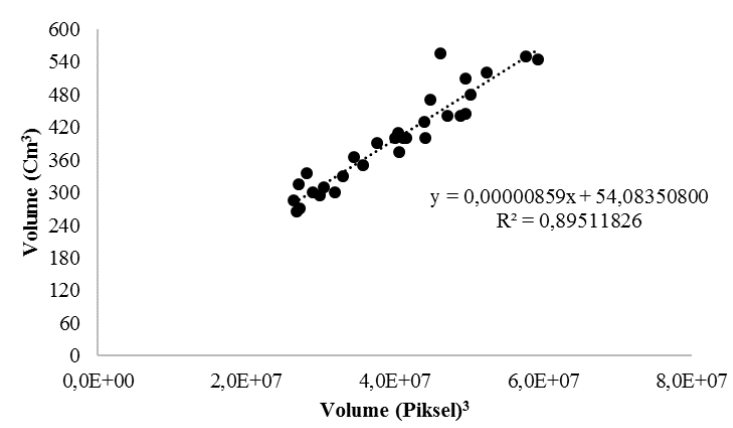

(b)

Gambar 1. Hubungan antara volume citra dengan massa dan volume buah alpukat metode eccentricity

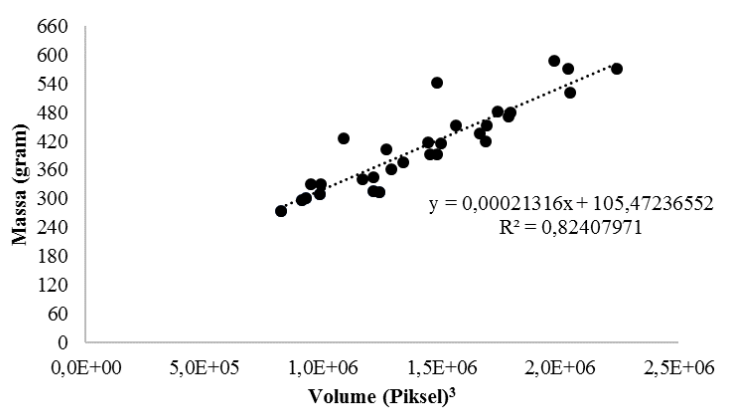

(a)

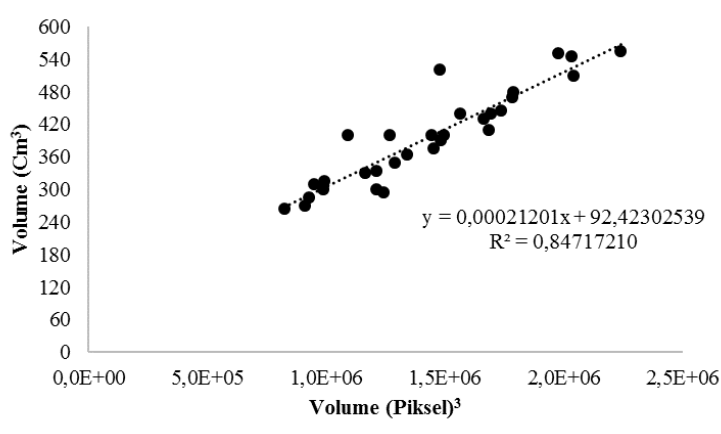

(b)

Gambar 2. Hubungan antara volume citra dengan massa dan volume buah alpukat metode irisan 


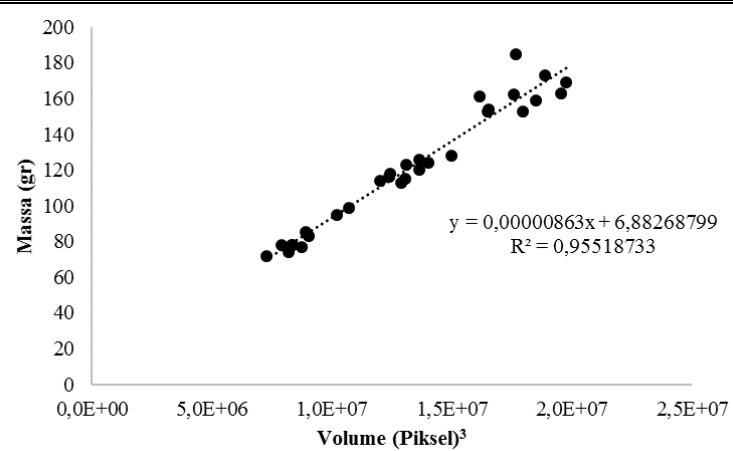

(a)

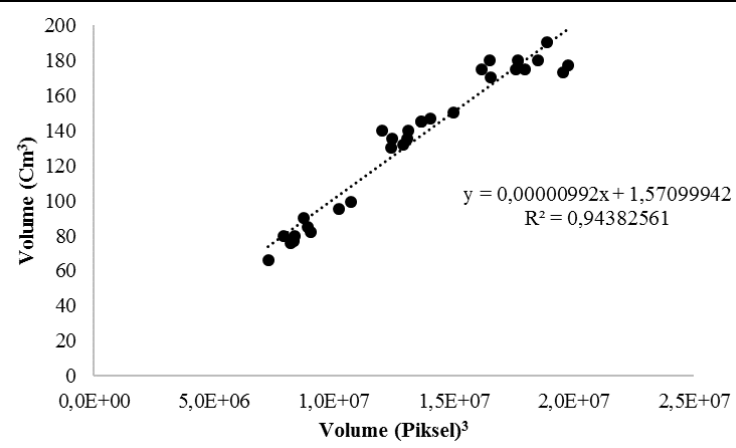

(b)

Gambar 3. Hubungan antara volume citra dengan massa dan volume buah jeruk metode eccentricity

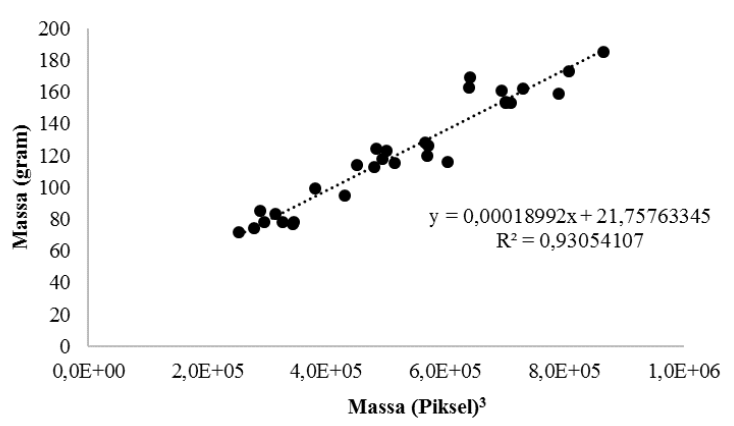

(a)

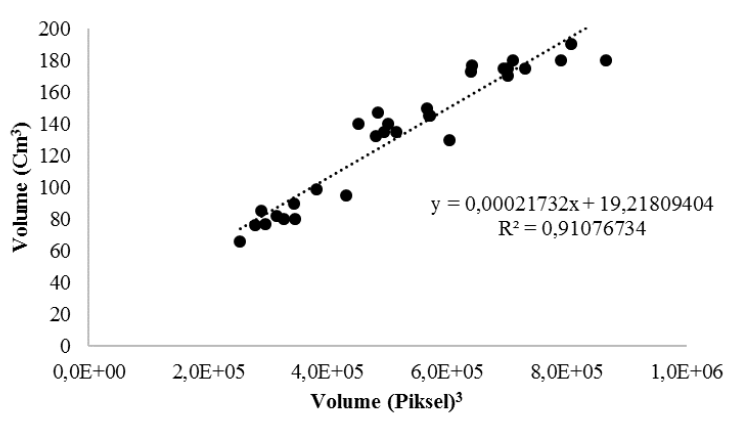

(b)

Gambar 4. Hubungan antara volume citra dengan massa dan volume buah jeruk metode irisan

Berdasarkan Gambar 1, 2, 3 dan 4 diatas, dapat diperoleh bahwa nilai koefisien determinasi massa dan volume menggunakan metode eccentricity pada buah alpukat sebesar 0,901 dan 0,895. Sedangkan nilai koefisien determinasi massa dan volume menggunakan metode irisan sebesar 0,824 dan 0,847. Nilai koefisien determinasi massa dan volume menggunakan metode eccentricity pada buah jeruk sebesar 0,955 dan 0,934. Sedangkan nilai koefisien determinasi massa dan volume menggunakan metode irisan sebesar 0,930 dan 0,910. Dapat dilihat bahwa koefisien determinasi metode eccentricity pada buah alpukat dan jeruk lebih baik dibandingkan dengan metode irisan.

Pendugaan massa dan volume buah dilakukan dengan menggunakan persamaan linier yang diperoleh dari Gambar 1,2,3 dan 4. Masing-masing sebanyak 15 sampel buah alpukat dan buah jeruk digunakan untuk mengetahui persentase ketepatan pendugaan. Tabel 2 menunjukkan sebanyak 94,12\% dan 92,85\% ketepatan menggunakan metode eccentricity pada buah alpukat,Tabel 3 menunjukkan sebanyak 96,58\% dan 93,08\% ketepatan menggunakan metode eccentricity pada buah jeruk, Tabel 4 menunjukkan sebanyak 93,60\% dan 94,00\% menggunakan metode irisan pada buah alpukat dan Tabel 5 menunjukkan sebanyak $92,54 \%$ dan $90,30 \%$ pada buah jeruk. 
Tabel 2. Persentase ketepatan pendugaan massa dan volume pada buah alpukat metode eccentricity

\begin{tabular}{crrrrrr}
\hline No & $\begin{array}{c}\text { Massa } \\
\text { Perhitungan } \\
\text { Citra (gram) }\end{array}$ & $\begin{array}{c}\text { Massa Manual } \\
\text { (gram) }\end{array}$ & $\begin{array}{c}\% \\
\text { Ketepatan }\end{array}$ & $\begin{array}{c}\text { Volume } \\
\text { Perhitungan } \\
\text { Citra }\left(\mathrm{cm}^{3}\right)\end{array}$ & $\begin{array}{c}\text { Volume } \\
\text { Manual }\left(\mathrm{cm}^{3}\right)\end{array}$ & $\begin{array}{c}\% \\
\text { Ketepatan }\end{array}$ \\
\hline 1 & 481,84 & 565 & 85,28 & 465,86 & 555 & 83,94 \\
2 & 496,40 & 520 & 95,46 & 480,09 & 510 & 94,14 \\
3 & 472,88 & 520 & 90,94 & 457,09 & 500 & 91,42 \\
4 & 584,03 & 570 & 97,60 & 565,83 & 540 & 95,44 \\
5 & 521,82 & 550 & 94,88 & 504,97 & 545 & 92,65 \\
6 & 398,34 & 384 & 96,40 & 384,16 & 350 & 91,11 \\
7 & 396,26 & 400 & 99,06 & 382,12 & 390 & 97,98 \\
8 & 449,81 & 435 & 96,71 & 434,51 & 450 & 96,56 \\
9 & 369,60 & 367 & 99,30 & 356,04 & 350 & 98,30 \\
10 & 431,22 & 435 & 99,13 & 416,33 & 420 & 99,13 \\
11 & 350,88 & 321 & 91,48 & 337,73 & 310 & 91,79 \\
12 & 273,20 & 310 & 88,13 & 261,73 & 295 & 88,72 \\
13 & 334,66 & 310 & 92,63 & 321,86 & 290 & 90,10 \\
14 & 305,25 & 345 & 88,48 & 293,09 & 335 & 87,49 \\
15 & 308,31 & 320 & 96,35 & 296,07 & 315 & 93,99 \\
\hline Rata-Rata & 411,63 & 423,47 & 94,12 & 397,16 & 410,33 & 92,85 \\
\hline Sim
\end{tabular}

Sumber : Hasil Analisis (2019)

Tabel 3. Persentase ketepatan pendugaan massa dan volume pada buah jeruk metode eccentricity

\begin{tabular}{crrrrrr}
\hline No & $\begin{array}{c}\text { Massa } \\
\text { Perhitungan } \\
\text { Citra (gram) }\end{array}$ & $\begin{array}{c}\text { Massa Manual } \\
\text { (gram) }\end{array}$ & $\begin{array}{c}\% \\
\text { Ketepatan }\end{array}$ & $\begin{array}{c}\text { Volume } \\
\text { Perhitungan } \\
\text { Citra }\left(\mathrm{cm}^{3}\right)\end{array}$ & $\begin{array}{c}\text { Volume } \\
\text { Manual }\left(\mathrm{cm}^{3}\right)\end{array}$ & $\begin{array}{c}\% \\
\text { Ketepatan }\end{array}$ \\
\hline 1 & 152,60 & 157 & 97,20 & 169,07 & 175 & 96,61 \\
2 & 167,93 & 159 & 94,68 & 186,69 & 165 & 88,38 \\
3 & 150,32 & 165 & 91,11 & 166,45 & 170 & 97,91 \\
4 & 161,96 & 154 & 95,08 & 179,83 & 175 & 97,31 \\
5 & 158,87 & 163 & 97,46 & 176,27 & 185 & 95,28 \\
6 & 114,95 & 119 & 96,60 & 125,79 & 140 & 89,85 \\
7 & 104,90 & 104 & 99,14 & 114,24 & 120 & 95,20 \\
8 & 101,86 & 110 & 92,60 & 110,74 & 125 & 88,59 \\
9 & 111,57 & 112 & 99,62 & 121,91 & 130 & 93,78 \\
10 & 111,75 & 119 & 93,91 & 122,12 & 135 & 90,46 \\
11 & 79,00 & 75 & 94,93 & 84,47 & 79 & 93,52 \\
12 & 75,81 & 74 & 97,61 & 80,81 & 71 & 87,86 \\
13 & 69,82 & 70 & 99,75 & 73,92 & 68 & 91,99 \\
14 & 72,63 & 72 & 99,13 & 77,15 & 79 & 97,66 \\
15 & 70,88 & 71 & 99,83 & 75,13 & 69 & 91,84 \\
\hline Rata-Rata & 113,66 & 114,93 & 96,58 & 124,31 & 125,73 & 93,08 \\
\hline
\end{tabular}

Sumber : Hasil Analisis (2019) 
Tabel 4. Persentase ketepatan pendugaan massa dan volume pada buah alpukat metode irisan

\begin{tabular}{crrrrrr}
\hline No & $\begin{array}{c}\text { Massa } \\
\text { Perhitungan } \\
\text { Citra (gram) }\end{array}$ & $\begin{array}{c}\text { Massa Manual } \\
\text { (gram) }\end{array}$ & $\begin{array}{c}\% \\
\text { Ketepatan }\end{array}$ & $\begin{array}{c}\text { Volume } \\
\text { Perhitungan } \\
\text { Citra }\left(\mathrm{cm}^{3}\right)\end{array}$ & $\begin{array}{c}\text { Volume } \\
\text { Manual }\left(\mathrm{cm}^{3}\right)\end{array}$ & $\begin{array}{c}\% \\
\text { Ketepatan }\end{array}$ \\
\hline 1 & 593,69 & 565 & 95,17 & 578,00 & 555 & 96,02 \\
2 & 549,87 & 520 & 94,57 & 534,43 & 510 & 95,43 \\
3 & 529,99 & 520 & 98,11 & 514,65 & 500 & 97,15 \\
4 & 550,84 & 570 & 96,64 & 535,39 & 540 & 99,15 \\
5 & 585,85 & 550 & 93,88 & 570,21 & 545 & 95,58 \\
6 & 366,35 & 384 & 95,40 & 351,89 & 350 & 99,46 \\
7 & 419,85 & 400 & 95,27 & 405,11 & 390 & 96,27 \\
8 & 355,23 & 435 & 81,66 & 340,83 & 450 & 75,74 \\
9 & 352,32 & 367 & 96,00 & 337,94 & 350 & 96,55 \\
10 & 498,63 & 435 & 87,24 & 483,46 & 420 & 86,87 \\
11 & 372,59 & 321 & 86,15 & 358,10 & 310 & 86,57 \\
12 & 316,88 & 310 & 97,83 & 302,69 & 295 & 97,46 \\
13 & 323,09 & 310 & 95,95 & 308,87 & 290 & 93,89 \\
14 & 359,15 & 345 & 96,06 & 344,73 & 335 & 97,18 \\
15 & 340,37 & 320 & 94,01 & 326,06 & 315 & 96,61 \\
\hline Rata-Rata & 434,31 & 423,47 & 93,60 & 419,49 & 410,33 & 94,00 \\
\hline Sit
\end{tabular}

Sumber : Hasil Analisis (2019)

Tabel 5. Persentase ketepatan pendugaan massa dan volume pada buah jeruk metode irisan

\begin{tabular}{crrrrrr}
\hline No & $\begin{array}{r}\text { Massa } \\
\text { Perhitungan } \\
\text { Citra (gram) }\end{array}$ & $\begin{array}{c}\text { Massa Manual } \\
\text { (gram) }\end{array}$ & $\begin{array}{c}\% \\
\text { Ketepatan }\end{array}$ & $\begin{array}{c}\text { Volume } \\
\text { Perhitungan } \\
\text { Citra }\left(\mathrm{cm}^{3}\right)\end{array}$ & $\begin{array}{c}\text { Volume } \\
\text { Manual }\left(\mathrm{cm}^{3}\right)\end{array}$ & $\begin{array}{c}\% \\
\text { Ketepatan }\end{array}$ \\
\hline 1 & 145,21 & 157 & 92,49 & 160,48 & 175 & 91,70 \\
2 & 141,76 & 159 & 89,16 & 156,54 & 165 & 94,87 \\
3 & 164,29 & 165 & 99,57 & 182,31 & 170 & 93,25 \\
4 & 154,40 & 154 & 99,74 & 171,00 & 175 & 97,71 \\
5 & 124,49 & 163 & 76,38 & 136,78 & 185 & 73,93 \\
6 & 122,53 & 119 & 97,12 & 134,53 & 140 & 96,09 \\
7 & 98,58 & 104 & 94,79 & 107,12 & 120 & 89,27 \\
8 & 93,61 & 110 & 85,10 & 101,43 & 125 & 81,15 \\
9 & 118,16 & 112 & 94,79 & 129,53 & 130 & 99,64 \\
10 & 126,78 & 119 & 93,86 & 139,40 & 135 & 96,85 \\
11 & 86,98 & 75 & 86,23 & 93,85 & 79 & 84,18 \\
12 & 73,46 & 74 & 99,27 & 78,38 & 71 & 90,59 \\
13 & 79,33 & 70 & 88,24 & 85,09 & 68 & 79,91 \\
14 & 74,96 & 72 & 96,05 & 80,09 & 79 & 98,63 \\
15 & 74,49 & 71 & 95,32 & 79,55 & 69 & 86,73 \\
\hline Rata-Rata & 111,93 & 114,93 & 92,54 & 122,41 & 125,73 & 90,30 \\
\hline Sumber $:$ Hasil Analisis $(2019)$ & & & & &
\end{tabular}

Penelitian ini dilakukan dengan menggunakan 2 algoritma yaitu algoritma berdasarkan eccentricity dan algoritma metode irisan, dengan parameter seperti massa dan volume. Hasil pengujian dengan algoritma berdasarkan eccentricity pada citra alpukat untuk pendugaan massa didapatkan tingkat akurasi dengan rata-rata sebesar $94,12 \%$, untuk pendugaan volume didapatkan tingkat akurasi dengan rata-rata sebesar $92,85 \%$. Pada citra jeruk untuk pendugaan massa didapatkan tingkat akurasi dengan rata-rata sebesar 
96,58\%, sedangkan untuk pendugaan volume didapatkan tingkat akurasi dengan rata-rata sebesar 93,08\%. Pada hasil pengujian dengan algoritma metode irisan pada citra alpukat untuk pendugaan massa didapatkan tingkat akurasi dengan rata-rata sebesar 93,60\%, untuk pendugaan volume didapatkan tingkat akurasi dengan rata-rata sebesar 94,00\%. Pada citra jeruk untuk pendugaan massa didapatkan tingkat akurasi dengan rata-rata sebesar 92,54\%, sedangkan untuk pendugaan volume didapatkan tingkat akurasi dengan rata-rata sebesar $90,30 \%$.

Tingkat akurasi volume jeruk yang diprediksi menggunakan teknologi pengolahan citra dengan algoritma berdasarkan kriteria bentuk (eccentricity) didapatkan hasil persentase yang lebih tinggi dibandingkan menggunakan algoritma dengan metode irisan. Hal ini dikarenakan panjang, lebar, dan tinggi buah jeruk memiliki nilai ukuran yang hampir sama, sehingga algoritma berdasarkan kriteria bentuk (eccentricity) lebih mudah memprediksi volume jeruk dan lebih akurat. Sedangkan tingkat akurasi volume buah alpukat yang diprediksi dengan menggunakan metode irisan didapatkan hasil yang lebih tinggi dibandingkan dengan algoritma berdasarkan kriteria bentuk (eccentricity), dikarenakan metode irisan ini dapat menghitung tiap piksel pada objek dari setiap irisan yang dihasilkan hingga ukuran pada irisan tepi objek (buah). Sehingga algoritma dengan metode irisan ini menghasilkan akurasi prediksi yang lebih akurat dan sesuai digunakan pada buah yang berbentuk elips atau lonjong.

\section{KESIMPULAN DAN SARAN}

\section{Kesimpulan}

Berdasarkan data hasil dan pembahasan penelitian didapatkan bebearapa simpulan sepertiberikut:

1. Teknologi pengolahan citra digital dapat digunakan untuk menduga massa dan volume pada buah alpukat dan buah jeruk.

2. Pendugaan massa dan volume buah alpukat menggunakan metode eccentricity diperoleh tingkat rata-rata akurasi masing-masing sebesar 94,12\% dan 92,85\%. Sedangkan menggunakan metode irisan diperoleh tingkat rata-rata akurasi masa dan volume masing-masing sebesar $93,60 \%$ dan $94,00 \%$.

3. Pendugaan massa dan volume buah jeruk menggunakan eccentricity diperoleh tingkat rata-rata akurasi masing-masing sebesar 96,58\% dan 93,08\%. Sedangkan menggunakan metode irisan diperoleh tingkat rata-rata akurasi masa dan volume masing-masing sebesar $92,54 \%$ dan $90,30 \%$.

4. Penggunaan metode eccentricity lebih sesuai digunakan pada buah yang memiliki bentuk bulat (bola), sedangkan metode irisan lebih sesuai digunakan pada buah yang memiliki bentuk elips ataupun lonjong.

\section{Saran}

Perlu dilakukan penelitian lanjutan dengan menggunakan komoditi yang bervariasi dengan penambahan jumlah sampel yang lebih banyak, serta mencoba proses pengambilan gambar dengan menggunakan kamera 3 dimensi. 


\section{DAFTAR PUSTAKA}

Akar, R dan C. Aydin. 2005. Some physical properties of gumbo fruit varieties. J. Food Eng. $66: 387-393$.

Hahn, F dan S. Sanchez. 2000. Carrot volume evaluation using imaging algorithms. J. Agric. Eng. Res. 75 : 243-249.

Iqbal, M.S., A. Gopaldan A.S.V. Sarma. 2011. Volume estimation of apple fruits using image processing. Proceddings of Internasional Conference on Image Information Processing.

Kementerian Pertanian. 2012. Buku Informasi Sayuran dan Tanaman Obat. Direktorat Jendral Holtikultura.

Plataniotis dan Venetsanopoulos. 2000. Color Image Processing and Applications. SpringerVerlag, New York.

Riddle D.F. 1979. Calculus and Analytic Geometry.Wadsworth Publishing Company, Inc., Belmont, CA, USA.

Venekatesh, G.V.,Iqbal, S, Md., A.Gopal dan D. Ganesan. 2015. Estimation of volume and mass of axi-symmetric fruits using image processing technique. Internasional Journal of Food Properties. $18: 608-626$. 